\title{
Rennet-induced gelation of concentrated milk in the presence of sodium caseinate: Differences between milk concentration using ultrafiltration and osmotic stressing
}

\author{
P. Krishnankutty Nair ${ }^{1,2}$ and M. Corredig \\ Department of Food Science, University of Guelph, Ontario, Canada N1G 2W1
}

\begin{abstract}
Concentrating milk is a common unit operation in the dairy industry. With the reduction of water, the particles interact more frequently with each other and the functionality of the casein micelles may depend on the interactions occurring during concentration. The objective of this research was to investigate the effect of concentration on the renneting properties of the casein micelles by comparing 2 concentration methods: ultrafiltration and osmotic stressing. Both methods selectively concentrate the protein fraction of milk, while the composition of the soluble phase is unaltered. To evaluate possible differences in the rearrangements of the casein micelles during concentration, renneting properties were evaluated with or without the addition of soluble caseins, added either before or after concentration. The results indicate that casein micelles undergo rearrangements during concentration and that shear during membrane filtration may play a role in affecting the final properties of the milk.
\end{abstract}

Key words: concentrated milk, renneting, casein micelle, ultrafiltration, osmotic stressing

\section{INTRODUCTION}

Evaporation and membrane filtration are the most common methods of concentration in dairy technology and their effects on the colloidal properties of the casein micelles have been widely studied (Karlsson et al., 2007; Dahbi et al., 2010; Ferrer et al., 2011). Membrane separation processes have been used to standardize milk and change its composition for further processing. The physico-chemical properties of the milk and its serum can be carefully controlled by the selectivity of the membrane used. However, the integrity of the micelles after UF, whereby only lactose and soluble components

Received May 13, 2014.

Accepted September 20, 2014.

${ }^{1}$ Corresponding author: pkrishna@uoguelph.ca

${ }^{2}$ Current address: Saputo Dairy Products Canada, 122 Wakooma Street, Saskatoon, Saskatchewan, Canada S7K 3P1. are transmitted and the protein is retained in the retentate, is still under debate (Singh, 2007; Alexander et al., 2011; Ferrer et al., 2011).

Changes in the processing functionality of concentrated milk are caused by several factors, of which an important factor is ionic equilibrium, especially the changes in soluble and colloidal calcium (Srilaorkul et al., 1991; Alexander et al., 2011). The increased interactions between the casein micelles due to their increased volume fraction may also play a major role (Bienvenue et al., 2003). The functional properties of concentrated milk obtained by membrane processing have been widely studied, particularly for cheese-making applications (St-Gelais et al., 1998; Waungana et al., 1998; Henning et al., 2004). Little proof is available that rearrangements occur to the structure of casein micelles during UF because their composition does not seem to be affected. When optimizing structure and function of these technologically important protein particles, it would help to know whether rearrangements occur. Some reports describe changes in calcium phosphate equilibrium as well as size distribution (McKenna, 2000; Singh, 2007; Ferrer et al., 2011). However, in most studies, UF is combined with diafiltration, which drastically changes the serum composition of the retentate.

Rennet-induced gelation is an important functionality of the casein micelles and is a useful technique to evaluate changes to the micelle surface. For example, it has been shown that the interactions between lowmolecular-weight emulsifiers, such as polysorbates, and casein micelles affect the secondary stage of rennetinduced gelation (Ion Titapiccolo et al., 2010). In addition, small changes in calcium concentration can adversely affect milk aggregation (Choi et al., 2007).

During renneting, the enzyme chymosin specifically cleaves the protective layer of $\kappa$-casein from the surface of the casein micelles; this reaction results in the loss of steric stabilization, leaving hydrophobic and calcium-sensitive patches on the surface of the particles (Dalgleish, 1992; de Kruif, 1992). When more than 90\% of the caseinomacropeptide (CMP) has been removed, the secondary phase of rennet aggregation begins (Dal- 
gleish, 1992; Sandra et al., 2007), which is moderated by free $\mathrm{Ca}^{2+}$ (Lucey, 2009). Modification of the surface of the micelle is particularly critical to the secondary phase of rennet aggregation. For example, interactions of whey protein with the surface of casein micelles impair the secondary stage of casein aggregation (Vasbinder et al., 2003; Kethireddipalli et al., 2011). Rennet-induced gelation could then be used to evaluate whether changes have occurred to the polyelectrolyte surface layer of the casein micelles.

It has been extensively demonstrated that, during concentration, casein micelles behave as hard spheres (Bouchoux et al., 2009b; Nair et al., 2013, 2014), meaning that their colloidal properties are dictated by changes to the surface. In the present work, we hypothesized that membrane filtration causes rearrangements to the structure of the casein micelles. To test this hypothesis, milk was concentrated using UF or osmotic stressing, and the renneting properties were tested. Osmotic stress is an alternative process for concentrating milk that is considered noninvasive and is carried out under quiescent conditions. This technique has already been successfully used to characterize concentrated milk systems (Farrer and Lips, 1999; Bouchoux et al., 2009a,b). By dialysing milk against milk permeate containing a stressing polymer, it is possible to maintain the original serum environment for casein micelles and obtain concentrated milk with a composition equivalent to that of UF milk. In short, this allows investigation of the fundamental aspects of concentrated systems and comparison of UF retentates to a casein micelle suspension with the same volume fraction but obtained without mechanical shear.

To further test possible rearrangements, casein micelles were concentrated in the presence of soluble caseins. It has been previously demonstrated that in skim milk, addition of sodium caseinate (NaCas; $\geq 2 \mathrm{~g} / \mathrm{L}$ ) inhibits aggregation of the casein micelles (Gaygadzhiev et al., 2012). Similar amounts of NaCas were added before or after concentration. In spite of the widespread application of membrane filtration in dairy processing, little is understood about the structural changes occurring to the casein micelles during concentration. By adding soluble caseins and measuring changes in rennet gelation behavior, it may be possible to determine whether rearrangements occur in casein micelles during concentration.

\section{MATERIALS AND METHODS}

\section{Preparation of Skim Milk and Permeate}

Fresh milk was collected (University of Guelph Dairy Research Station, Ponsonby, ON, Canada) and sodium azide $(0.2 \mathrm{~g} / \mathrm{L})$ was added to prevent microbial growth. Milk fat was separated by centrifuging the milk at $4,000 \times g$ for $25 \mathrm{~min}$ at $4^{\circ} \mathrm{C}(\mathrm{J} 2-21$ centrifuge, Beckman Coulter Canada Inc., Mississauga, ON, Canada) and filtering 4 times through Whatman fiberglass filter (Fisher Scientific, Mississauga, ON, Canada; Nair et al., 2013).

To prepare permeate, skim milk powder (Gay Lea Foods Cooperative, Guelph, ON, Canada) was reconstituted at the rate of $100 \mathrm{~g} / \mathrm{L}$ of solids. It was then prepared by UF through an Optisep Filter module (Smartflow Technologies, Apex, NC) with a 10-kDa molecular mass cutoff at ambient temperature. The average ionic composition of the UF permeate was approximately 20 $\mathrm{m} M \mathrm{Na}^{+}, 40 \mathrm{~m} M \mathrm{~K}^{+}, 10 \mathrm{~m} M \mathrm{Ca}^{2+}, 30 \mathrm{~m} M \mathrm{Cl}^{-}, 10 \mathrm{~m} M$ phosphate, and $10 \mathrm{~m} M$ citrate, in agreement with previous reports (Jenness and Koops, 1962).

\section{Preparation of Concentrated Milk}

Milk was concentrated using osmotic stressing as described in detail by Nair et al. (2013, 2014). All experiments were carried out by dispersing polyethylene glycol (PEG; Fluka, Oakville, ON, Canada) at a rate of $80 \mathrm{~g} / \mathrm{L}$ in permeate. Sodium azide $(0.2 \mathrm{~g} / \mathrm{L})$ was also added. The osmotic pressure experiment was conducted at $4^{\circ} \mathrm{C}$ for $18 \mathrm{~h}$ to minimize sample degradation. At the end of osmotic stressing using PEG, a volume fraction of $0.3 \pm 0.03$ (corresponding to approximately $3 \times$ concentration) was obtained. Milk was also concentrated by UF, $3 \times$ the original volume, based on volume reduction. Ultrafiltration was carried out using a laboratory-scale membrane unit (PLGC10k regenerated cellulose cartridge, Millipore Corp., Bedford, MA) at $22^{\circ} \mathrm{C}$.

Concentrated milk was also prepared with additional soluble casein (NaCas). In both osmotic stressing and UF samples, NaCas (2 g/L) was added to skim milk and stirred for $2 \mathrm{~h}$ at room temperature. This concentration ratio has been shown to inhibit the formation of rennet gel (Gaygadzhiev et al., 2012). This sample was then subjected to osmotic concentration or UF as described before. Sodium caseinate was also added after concentration to concentrated milk samples, using a similar ratio $(6 \mathrm{~g} / \mathrm{L})$ and stirred for $2 \mathrm{~h}$ at room temperature. Similarly, control samples with no NaCas added and samples with $\mathrm{NaCas}$ added before concentration were stored at room temperature for $2 \mathrm{~h}$ to reverse the changes in the soluble caseins and mineral equilibria. Both control concentrated milk samples had lower amounts of protein compared with the samples with added NaCas (added before or after), to maintain the same volume fraction of casein micelles. 


\section{Separation of Centrifugal Supernatant from Concentrated Samples}

Milk samples were centrifuged at $100,000 \times g$ for 1 $\mathrm{h}$ at $20^{\circ} \mathrm{C}$ (Beckman Coulter Optima LE-80K ultracentrifuge, rotor type $70.1 \mathrm{Ti}$, Beckman Coulter Canada Inc.) to separate the casein micelles from the serum fraction. The supernatant was carefully recovered using a pasteur pipette and then filtered twice using 0.45and $0.22-\mu \mathrm{m}$ filters.

\section{Ion Exchange Chromatography}

The soluble fraction was analyzed for caseins using ion exchange chromatography equipped with an AKTA purifier (900 series, GE Biosciences, Baie d'Urfe, Quebec, Canada) and a UV-900 detector (set at $280 \mathrm{~nm}$; Holland et al., 2010). In brief, a sample buffer consisting of $0.2 \mathrm{M}$ sodium acetate and $6 \mathrm{M}$ urea at $\mathrm{pH} 3.5$ was prepared, 5 -mL aliquots of supernatant were added to $5 \mathrm{~mL}$ of sample buffer, and then $3.6 \mathrm{~g}$ of urea and $0.013 \mathrm{~g}$ of sodium acetate were added. The samples were stirred for $1 \mathrm{~h}$, the $\mathrm{pH}$ was adjusted to 7.0, and $\beta$-mercaptoethanol $(0.150 \mu \mathrm{L})$ was added. The samples were again stirred for $1 \mathrm{~h}$ and the $\mathrm{pH}$ was adjusted to 3.5 with $1 \mathrm{M} \mathrm{HCl}$ and stirred for $5 \mathrm{~min}$. The total volume was then adjusted to $15 \mathrm{~mL}$ (if needed) by the addition of MilliQ water (Millipore, Bedford, MA) and stirred for $5 \mathrm{~min}$. The samples were filtered through a $0.45-\mu \mathrm{m}$ syringe filter (Millex GV, Millipore) before injection; $500 \mu \mathrm{L}$ was injected onto a $1-\mathrm{mL}$ cation exchange HP SP column (GE Biosciences) eluting at 1 $\mathrm{mL} / \mathrm{min}$ with $0.2 \mathrm{M}$ sodium acetate, $6 \mathrm{M}$ urea buffer at $\mathrm{pH} 3.5$ using a gradient of $\mathrm{NaCl}$ as previously reported (Holland et al., 2010).

\section{Rennet Gelation}

Rennet [Chymax Ultra, 750 International Milk Clotting Units (IMCU) $/ \mathrm{mL}$; Chr. Hansen, Milwaukee, WI] was diluted 1:100 in Milli-Q water immediately before use, and then added to milk at the rate of 0.03 $\mathrm{IMCU} / \mathrm{mL}$ of milk. The extent of CMP released during rennet proteolysis was measured using reverse phaseHPLC (López-Fandino et al., 1993). Two-milliliter milk samples were incubated at $30^{\circ} \mathrm{C}$, and at appropriate time intervals to observe the enzyme kinetics; $4 \mathrm{~mL}$ of $3 \%$ percholoric acid was vortexed to stop the reaction. After refrigeration overnight and equilibration to room temperature, samples were separated by centrifugation at $4,500 \times g$ for 15 min using an Eppendorf 5415D centrifuge (Brinkmann Instruments Ltd., Mississauga, ON, Canada). The supernatants were filtered through $0.45-\mu \mathrm{m}$ Millex-GV filter units (Millipore). The area under the peaks detected at $210 \mathrm{~nm}$ was calculated and the total amount of CMP was expressed relative to the maximum amount (defined as the value at plateau) of CMP released from the same concentrated sample.

The preceding stages of gelation were followed using transmission diffusing wave spectroscopy (DWS). This technique was used to determine the dynamic behavior of colloidal particles in the concentrated suspensions (Weitz and Pine, 1993). The measurements were carried out as described in Nair et al. $(2013,2014)$.

The sample with rennet $(\sim 1.5 \mathrm{~mL})$ was poured into a 5-mm optical glass cuvette (Hellma Canada Ltd., Concord, ON, Canada). The cuvette was placed in a water bath at a temperature of $30^{\circ} \mathrm{C}$. The sample was illuminated by a solid-state laser light with a wavelength of $532 \mathrm{~nm}$ and a power of $350 \mathrm{~mW}$ (Coherent, Santa Clara, CA).

Development of the gel was also measured using a controlled stress rheometer (Paar Physica MC 301, Anton Paar, Graz, Austria), using a cone-and-plate geometry with a set gap of $0.51 \mathrm{~mm}$. All measurements were made at $30^{\circ} \mathrm{C}$. The equipment was run in controlled strain mode, $1 \%$ strain, $1 \mathrm{~Hz}$ frequency. Mineral oil was used to prevent the evaporation of the samples.

The measurements of DWS and rheology were made simultaneously on 2 fractions of the same renneted milk. Samples of concentrated milk were equilibrated at $30^{\circ} \mathrm{C}$ for at least $15 \mathrm{~min}$ before rennet addition (at a ratio of $0.03 \mathrm{IMCU} / \mathrm{mL}$ of milk and stirred for $30 \mathrm{~s}$ ). The samples were then simultaneously loaded into to the rheometer and transmission DWS equipment. The DWS and rheology measurements were started simultaneously at approximately 3 min after rennet addition.

\section{Separation of Centrifugal Supernatant from Renneted Samples}

Immediately after rennet addition, the samples were transferred into Beckman Coulter centrifuge tubes (Beckman Coulter Canada Inc.) and incubated at $30^{\circ} \mathrm{C}$ for $150 \mathrm{~min}$ in a water bath. At the end of incubation period, the samples were centrifuged at $100,000 \times g$ for $1 \mathrm{~h}$ at $30^{\circ} \mathrm{C}$ as described above. The supernatant was carefully recovered using a pasteur pipette, and then filtered twice using 0.45 - and $0.22-\mu \mathrm{m}$ filters.

\section{Calcium Measurements}

Determination of soluble calcium in all samples was carried out using nonsuppressed ion chromatography (Rahimi Yazdi et al., 2010). The amount of soluble calcium in the concentrated milk was defined as the total calcium in the serum phase after $1 \mathrm{~h}$ of centrifugation at $100,000 \times g$. One milliliter of the centrifugal 
supernatant $(0.5 \mathrm{~mL})$ was mixed with $200 \mu \mathrm{L}$ of $1 \mathrm{M}$ $\mathrm{HCl}$ and adjusted to a final volume of $100 \mathrm{~mL}$ in a volumetric flask with HPLC-grade water. To decrease the interference of di- and tricarboxylic acids, mainly citrate, a preparative column chromatography (Kontes FlexColumn Economy columns, $1.0 \mathrm{~cm}$ i.d., $20 \mathrm{~cm}$ length, Fisher, Nepean, ON, Canada) was carried out with Amberlite IRA 958 (Fluka, Sigma, Steinheim, Germany) ion exchange resin. A solution of $\mathrm{NaCl}(100$ $\mathrm{g} / \mathrm{L})$ and $\mathrm{NaOH}(20 \mathrm{~g} / \mathrm{L})$ at a flow rate of $1 \mathrm{~mL} / \mathrm{min}$ for $30 \mathrm{~min}$ and subsequent rinsing with HPLC water at the same flow rate for $6 \mathrm{~h}$ were used to activate the resin. The samples $(50 \mathrm{~mL})$ were loaded at a flow rate of $1 \mathrm{~mL} / \mathrm{min}$, the first $25 \mathrm{~mL}$ discarded, and 2 aliquots $(12 \mathrm{~mL}$ each) were collected in sample vials for further analysis. These aliquots were then refrigerated until further analysis on an 861 Advanced Compact ion chromatograph ( $\Omega$ Metrohm ion analysis, Metrohm Ltd., Herisau, Switzerland). The temperatures of the column and detector were maintained at $30^{\circ} \mathrm{C}$. The instrument was operated with IC Net software (v. 2.3, Metrohm Ltd.).

\section{Particle Size Determination}

The particle size of the casein micelles was measured by dynamic light scattering (Zetasizer Nano-ZS, Malvern, Westborough, MA). After concentration, the milk samples were diluted approximately 1:2,000 in filtered (0.2- $\mu \mathrm{m}$ nylon filter; Fisher Scientific) milk permeate and analyzed.

\section{Statistical Analysis}

All experiments were carried out in triplicate (i.e., 3 separate milk batches), and means and standard errors are reported. Statistical significance was evaluated using ANOVA at $P<0.05$.

\section{RESULTS AND DISCUSSION}

\section{Composition of the Serum Phase}

Milk was concentrated to a comparable volume fraction $(0.30 \pm 0.03)$ using osmotic stressing or UF, without the use of diafiltration. Under the experimental conditions used in this study, soluble caseins or redispersed NaCas did not precipitate (HadjSadok et al., 2008).

The elution chromatograms of the soluble phase of milk concentrated by osmotic stressing or UF showed 5 main peaks, in agreement with previous reports (Holland et al., 2010). Milk concentrated using osmotic stressing contained a significantly higher amount of soluble caseins in (Figure 1A) compared with that concentrated by UF (Figure 1B). This was particularly noted in the peaks eluting at $8.4 \mathrm{~min}$ and after 17 min, corresponding to $\beta$-casein and the $\alpha_{S}$-caseins, respectively. In addition, these peaks were higher when NaCas was added. All peaks were higher than those of the $0.6 \%$ NaCas solution evaluated for reference.

We observed a statistically significant effect $(P<$ 0.05) of addition of NaCas: peaks were higher in samples where NaCas was added after concentrating the milk. When NaCas was added before concentration, a significant amount was transferred to the colloidal phase. The peak areas for the 3 treatments (control, NaCas added after and NaCas added before) differed significantly ( $P$

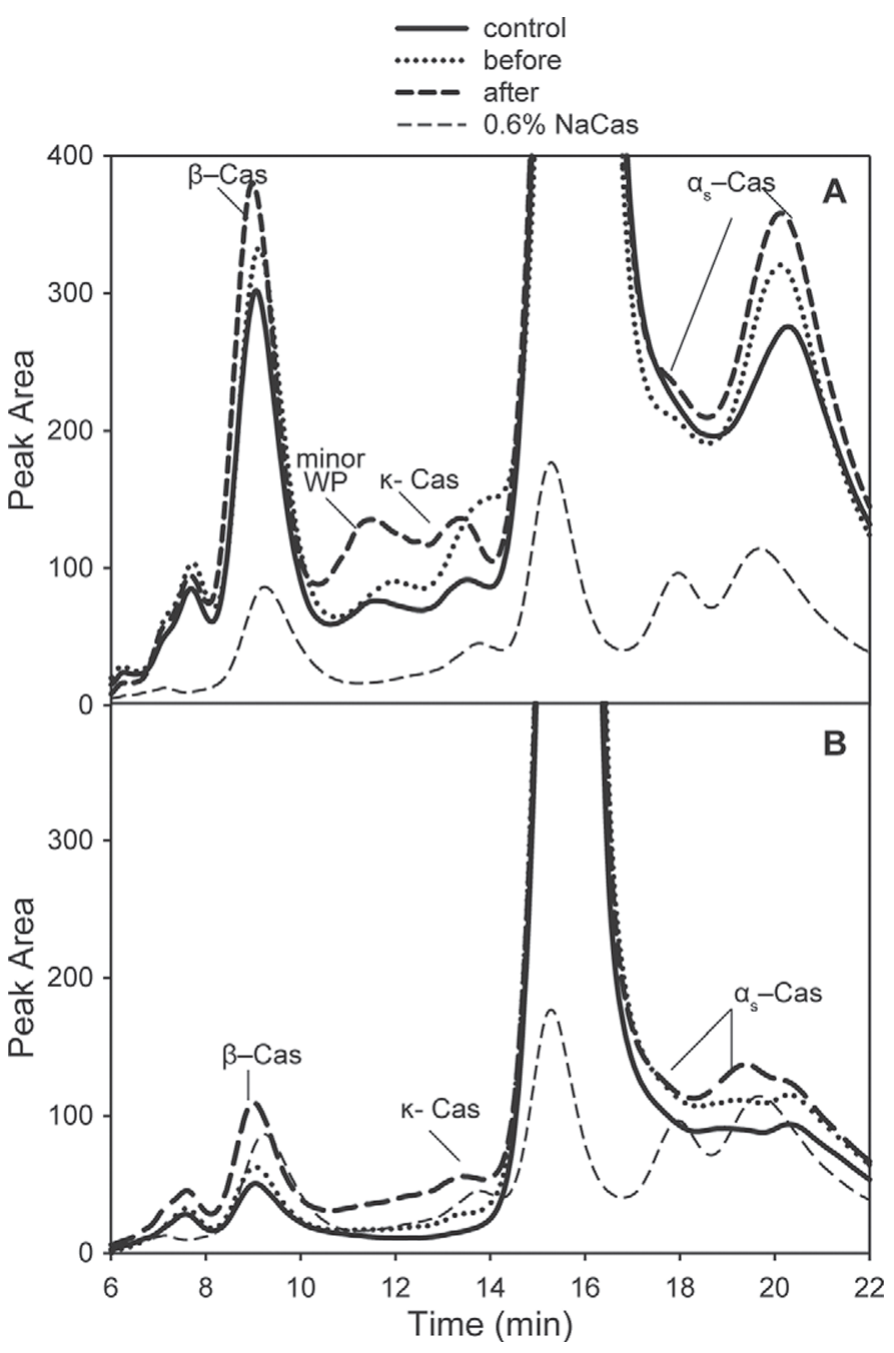

Figure 1. Ion exchange chromatography elution peak of centrifugal supernatants of milk concentrated by (A) osmotic stressing or (B) UF. Treatments were control (milk concentrated $3 \times$ ) and milk with sodium caseinate (NaCas) added before or after concentration. The profile of $0.6 \%$ NaCas solution is also shown (thin dashed line). Peaks of caseins (Cas) and minor whey proteins (WP) are shown. Data are representative of 3 separate experiments. 
$<0.001$ ) within concentrated milk treatment (for both UF and osmotic stressing).

The differences in the amounts of nonsedimentable caseins between Figure $1 \mathrm{~A}$ and $1 \mathrm{~B}$ may reflect differences in the process of concentration. Although osmotic stressing is considered a mild treatment of concentration, the continuous shear and transmembrane pressure applied to milk during UF may lead to some rearrangements of the structure of the casein micelles.

The levels of soluble calcium present in the supernatants of different types of concentrated milk are given in Table 1 . We detected no significant differences in soluble calcium levels for $3 \times$ concentrated control milk, irrespective of the method of concentration. The level of soluble calcium $(10 \mathrm{mM})$ was similar to that in skim milk reported in the literature (Lucey and Horne, 2009). On the other hand, milk concentrated by osmotic stressing with added $\mathrm{NaCas}$ showed significantly higher levels of serum calcium $(P<0.01)$ compared with UF milk, regardless of whether the caseins were added before or after heating. This discrepancy may be attributed in part to the greater amount of soluble casein, as shown in Figure 1. Being highly phosphorylated, soluble caseins will bind calcium. The free ionic calcium, $\mathrm{Ca}^{2+}$, in milk constitutes approximately $6 \%$ of the total calcium (Neville, 2005) and plays a major role in rennet-induced coagulation (Lucey, 2009).

\section{Light-Scattering Properties of Concentrates}

Using DWS, we were able to follow the diffusivity behavior of the casein micelles in situ, without dilution. The values of mean square displacement (MSD) as a function of time for the $3 \times$ concentrated milk and the milk samples with added NaCas are shown in Figure 2.

A linear relationship exists between particle MSD and time when the particles are free diffusing (Krall and Weitz, 1998). The linearity of the MSD plots was evident when plotted on a log-log scale or linear scale for all treatments. In Figure 2, the MSD values as a function of time are shown for concentrated milk with and without $\mathrm{NaCas}$ added, and straight lines are drawn

Table 1. Amount of soluble calcium $(\mathrm{m} M)$ recovered in the centrifugal supernatant of $3 \times$ milk concentrated by osmotic stress or UF with addition of sodium caseinate (NaCas) before or after concentration ${ }^{1}$

\begin{tabular}{lcc}
\hline Sample & $\begin{array}{c}\text { Osmotic } \\
\text { stress }\end{array}$ & $\mathrm{UF}$ \\
\hline Control & $10.2 \pm 0.5^{\mathrm{a}}$ & $10.35 \pm 0.1^{\mathrm{a}}$ \\
NaCas added before & $12.5 \pm 0.5^{\mathrm{b}}$ & $10.5 \pm 0.1^{\mathrm{a}}$ \\
NaCas added after & $12.5 \pm 0.5^{\mathrm{b}}$ & $10.35 \pm 0.1^{\mathrm{a}}$ \\
\hline a,b Letters indicate statistical & differences $(P<0.05)$ between treat- \\
ments. &
\end{tabular}

to illustrate possible deviations from linearity. All concentrates were similar in protein composition and ionic strength and, regardless of treatment, the casein micelles showed free diffusive Brownian motion. These results are in full agreement with previous work (Nair et al., 2014), wherein it was shown that at volume fractions $>0.32$, particle dynamics change to arrested subdiffusive motion when milk is concentrated by osmotic stressing.

When the samples were rediluted to 1:2,000 using milk serum, the apparent size of the micelles was not different between treatments, regardless of the amount of NaCas, the time of addition, or the method of concentration. Statistical analysis of the values of diffusion coefficient measured in undiluted UF and osmotic stressed milk (Table 2) demonstrated a significantly lower $(P<0.05)$ diffusion coefficient for casein micelles in milk concentrated by osmotic stressing compared with UF. Diffusion of a particle is affected by its size and the viscosity of the continuous phase. The elevated concentration of soluble caseins (Figure 1) increased the viscosity of the continuous phase, decreasing the diffusivity of the casein micelles.

\section{Rennet Gelation}

The rennet-induced gelation of the casein micelles in concentrated milk was followed using DWS and rheology. Figure 3 describes the development of the turbidity parameter, $1 / 1^{*}$ (where $1^{*}=$ photon transport mean free path, representing the length scale over which the direction of the light passing through a sample has been fully randomized; turbidity was measured as the

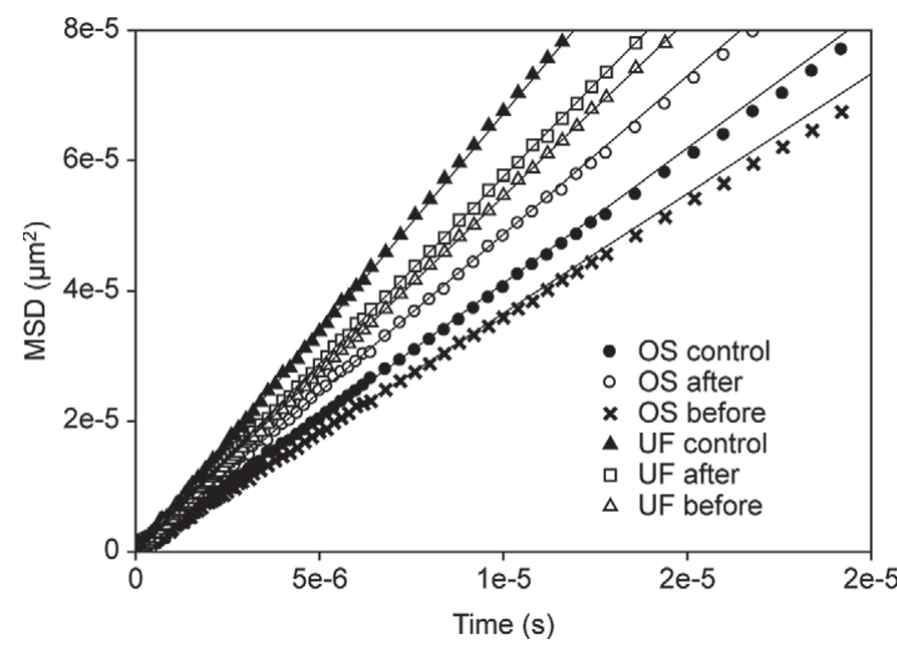

Figure 2. The mean square displacement values (MSD) for milk concentrated using osmotic stressing (OS) or UF. Treatments were control (milk concentrated $3 \times$ ) and milk with sodium caseinate added before or after concentration. Straight lines are drawn to guide the eye. 
Table 2. Values of diffusion coefficient and diameter of casein micelles for milk concentrated by osmotic stress or UF with addition of sodium caseinate (NaCas) before or after concentration ${ }^{1}$

\begin{tabular}{lccccc}
\hline & \multicolumn{2}{c}{ Diffusion coefficient, $10^{-12}\left(\mathrm{~m}^{2} / \mathrm{s}\right)$} & & \multicolumn{2}{c}{ Diameter $(\mathrm{nm})$} \\
\cline { 2 - 3 } \cline { 5 - 6 } Sample & $\begin{array}{c}\text { Osmotic } \\
\text { stress }\end{array}$ & $\mathrm{UF}$ & & $\begin{array}{c}\text { Osmotic } \\
\text { stress }\end{array}$ & $\mathrm{UF}$ \\
\hline Control & $0.71 \pm 0.03^{\mathrm{a}}$ & $1.2 \pm 0.03^{\mathrm{b}}$ & & $162.0 \pm 0.6^{\mathrm{a}}$ & $160.6 \pm 0.2^{\mathrm{a}}$ \\
NaCas added before & $0.65 \pm 0.03^{\mathrm{a}}$ & $1.2 \pm 0.03^{\mathrm{b}}$ & & $160.5 \pm 0.9^{\mathrm{a}}$ & $159.6 \pm 0.2^{\mathrm{a}}$ \\
NaCas added after & $0.65 \pm 0.07^{\mathrm{a}}$ & $1.0 \pm 0.03^{\mathrm{b}}$ & & $162.9 \pm 1.0^{\mathrm{a}}$ & $161.6 \pm 1.2^{\mathrm{a}}$ \\
\hline
\end{tabular}

$\overline{\mathrm{a}, \mathrm{b}}$ Letters indicate statistical differences $(P<0.05)$ between treatments.

${ }^{1}$ Values are the means $( \pm \mathrm{SE})$ of 3 independent experiments.

inverse of $1^{*}$ ), and apparent radius as a function of time from rennet addition for milk concentrated by osmotic stressing (Figure 3A) and UF (Figure 3B), with and without addition of NaCas. The point at which the radius increased rapidly indicated the aggregation time of the casein micelles. Figure 3A shows that, for osmotic stressing, the addition of soluble caseins to milk after concentration significantly hindered aggregation of the casein micelles. On the other hand, samples concentrated by osmotic stressing in the presence of NaCas showed behavior similar to that of control casein micelles. This was not the case for milk concentrated by UF: the UF milk showed behavior very similar to that of control samples, regardless of the addition of NaCas. In addition, the gelation point as measured by DWS was similar between osmotically stressed milk and UF milk controls. These results point to a modification of the casein micelle structure.

The early changes in $1 / 1^{*}$ during renneting (at about $40 \mathrm{~min}$ ) indicate changes in spatial correlation between the micelles before full aggregation commences, as discussed previously (Alexander and Dalgleish, 2004, 2007; Sandra et al., 2007). After the increase around $40 \mathrm{~min}$, the $1 / 1^{*}$ value reached a plateau at the point of gelation. The steep increase around 40 min indicated increasing interactions between the casein micelles. This increase corresponds to about $80 \%$ of CMP release, regardless of the casein micelles volume fraction (Sandra et al., 2011). In agreement with the radius data, the milk sample with NaCas added after concentration by osmotic stressing showed a different behavior for the $1 / 1^{*}$ parameter, and $1 / 1^{*}$ did not reach a plateau within experimental time (Figure 3A). We concluded that, although the presence of additional NaCas did not affect the UF samples, the addition of NaCas after concentration in the osmotic stressed milk inhibited rennet-induced aggregation of the casein micelles.

Although the light-scattering parameters shown in Figure 3 better describe the changes occurring in the preceding stages of the sol-gel transitions, rheological measurements are better suited to determine possible differences in structure development. The average gela- tion time and final elastic modulus $\left(\mathbf{G}^{\prime}\right)$ after $2 \mathrm{~h}$ of incubation are summarized in Table 3. Figure 4 shows the development of $\mathrm{G}^{\prime}$ as well as the loss tangent (tan $\boldsymbol{\delta}$, where $\delta$ is the phase angle). The time of gelation for

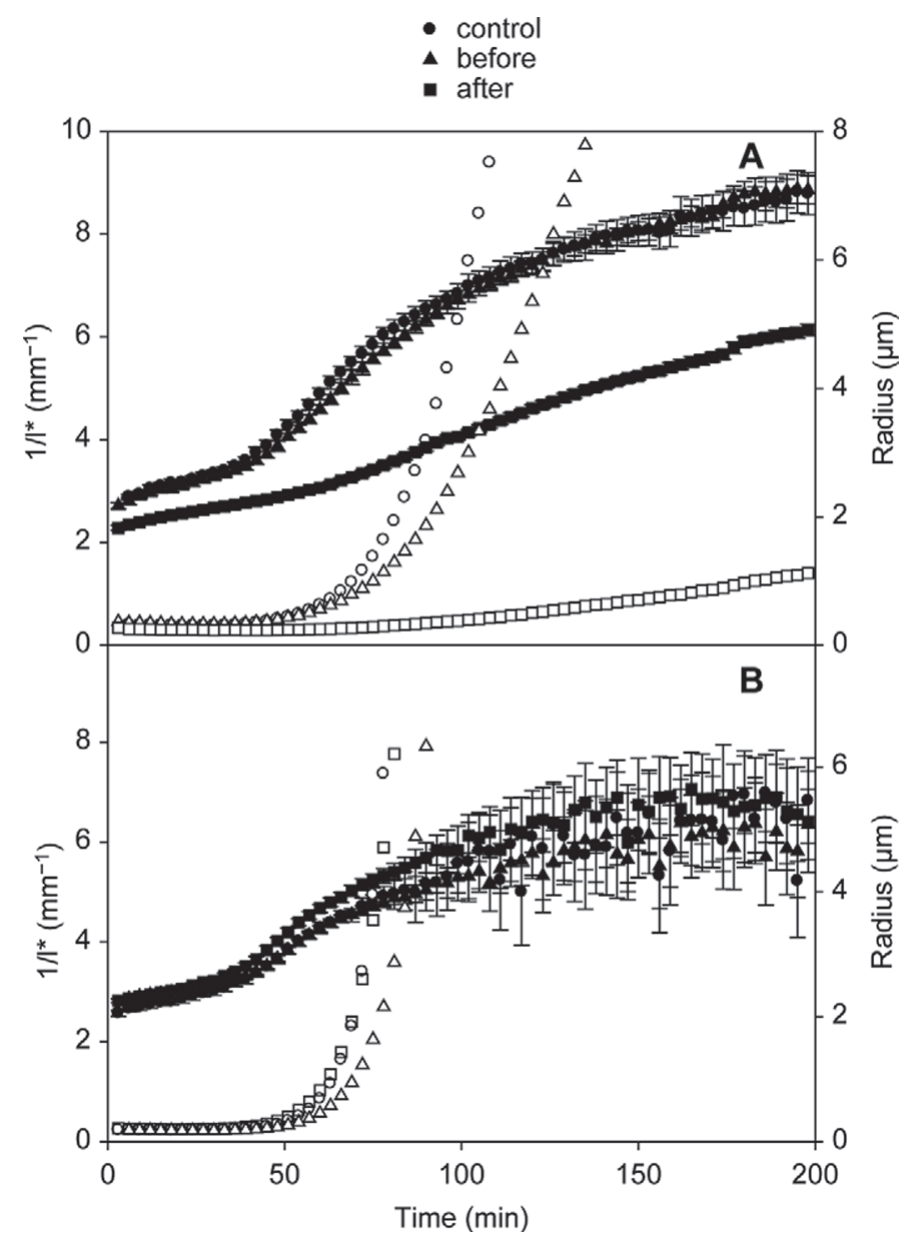

Figure 3. Development of turbidity parameter $\left[1 / 1^{*}\right.$ (photon transport mean free path); solid symbols], and apparent radius (open symbols), during renneting of milk concentrated using (A) osmotic stressing or (B) UF. Treatments were control (milk concentrated $3 \times$ ) and milk with sodium caseinate added before or after concentration. Error bars represent the standard error of turbidity parameter recorded during the experiment. 
control milk concentrated by UF was $70.1 \pm 3 \mathrm{~min}$, significantly faster $(P<0.05)$ than that for osmotically concentrated milk (100 $\pm 2 \mathrm{~min})$. This value was also in agreement with the aggregation time measured by DWS (Figure 3). The discrepancy in the time of gelation between the 2 controls may reflect the difference in the diffusivity of the casein micelles. In addition, the results indicate a difference in the rearrangement of the gel structure after gelation, as different values of $G^{\prime}$ were measured as a function of treatment. In general, UF samples resulted in stiffer gels compared with osmotically stressed samples. The osmotically concentrated control sample gelled later, and the value of $\mathrm{G}^{\prime}$ after $2 \mathrm{~h}$ from the gel point was $505 \pm 56 \mathrm{~Pa}$. The $\tan \delta$ behavior for control samples (osmotic stressing or UF) was typical of rennet-induced gels, with a steep decrease in $\tan \delta$ to a plateau with a final value of 0.26 , regardless of the mode of concentration. A low value of $\tan \delta$ indicates less flexibility and rearrangement in the intramicellar structure (van Vliet et al., 1991) and, during renneting, rearrangements happen at all levels from the microscopic to the mesoscopic to the macroscopic scale (Mellema et al., 2002).

For concentrated milk with NaCas added before concentration, the samples gelled at a similar time to that of the corresponding concentrated milk, regardless of mode of concentration. The value of $\mathrm{G}^{\prime}$ after $2 \mathrm{~h}$ of gelation was significantly lower $(P<0.05)$ for samples with added NaCas than for samples without. From Figure 1, it was clear that a part of added NaCas had moved to the colloidal phase and gelation still occurred.

Although some similarities were found in gelation behavior between osmotically stressed and UF concentrates in the samples concentrated in the presence of NaCas, the differences for milk samples with NaCas added after concentration were striking. When milk was concentrated by osmotic stressing and then NaCas was added (Figure 4A), gelation did not occur, confirming the light-scattering results shown in Figure 3A. On the other hand, in UF milk, the time of gelation did

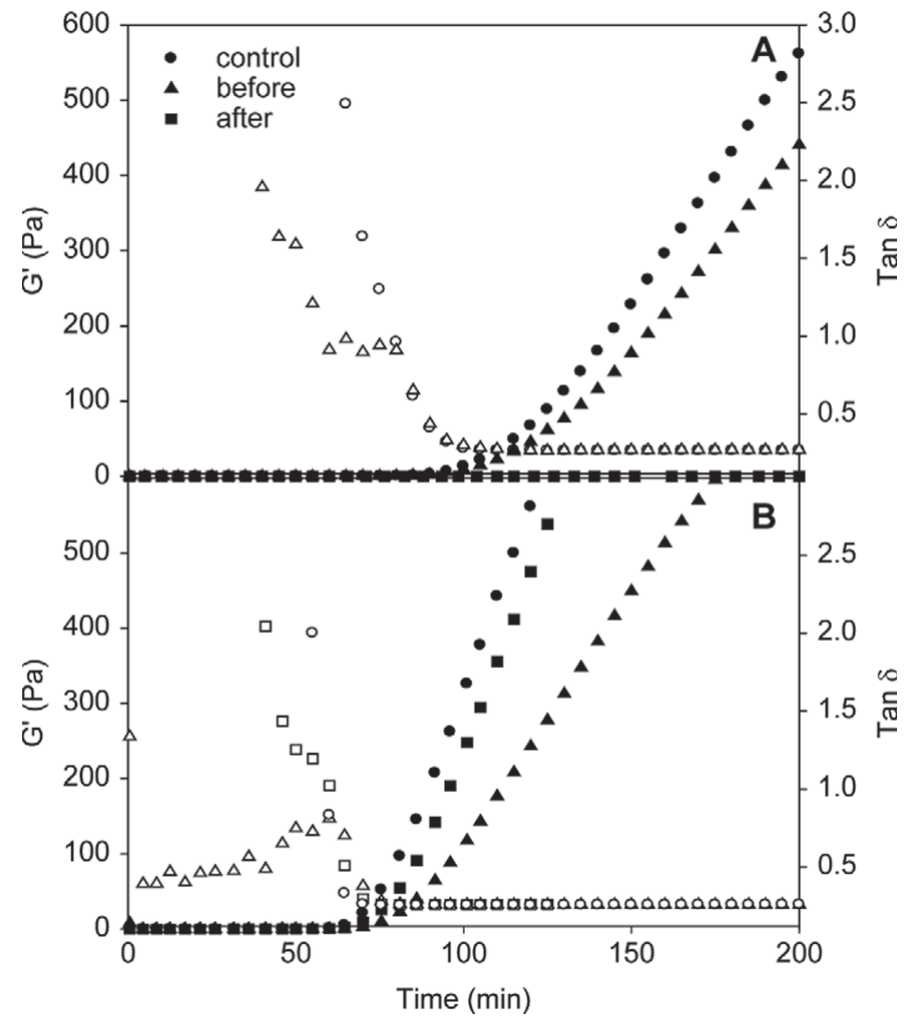

Figure 4. The development of elastic modulus $\left(\mathrm{G}^{\prime}\right.$; filled symbols) and loss tangent ( $\tan \delta$; empty symbols) during renneting of milk concentrated by (A) osmotic stressing or (B) UF. Treatments were control $(\bullet$; milk concentrated $3 \times)$ and milk with sodium caseinate added before $(\boldsymbol{\Lambda})$ or after $(\boldsymbol{\square})$ concentration. Values are for 1 representative run, averages and deviations are in Table 3.

not differ from that of the control (see Table 3). It is worth noting that in the case of NaCas added after concentration, the final value of $\mathrm{G}^{\prime}$ was of the same order of magnitude as for control milk, and the $\tan \delta$ behavior resembled that of control milk.

The gelation experiments indicated that method of concentration has a long-lasting effect on casein micelles. In the case of osmotic stressing, we also observed a discrepancy in the time of gelation measured by

Table 3. Rheological parameters measured during rennet-induced gelation of milk concentrated by osmotic stress and UF with addition of sodium caseinate (NaCas) before or after concentration ${ }^{1}$

\begin{tabular}{|c|c|c|c|c|}
\hline \multirow[b]{2}{*}{ Sample } & \multicolumn{2}{|c|}{ Osmotic stressing } & \multicolumn{2}{|c|}{ Ultrafiltration } \\
\hline & $\begin{array}{l}\text { Gel point } \\
\text { (min) }\end{array}$ & $\mathrm{G}^{\prime}$ after $2 \mathrm{~h}(\mathrm{~Pa})$ & $\begin{array}{l}\text { Gel point } \\
\text { (min) }\end{array}$ & $\begin{array}{c}\mathrm{G}^{\prime} \underset{(\mathrm{Pa})}{\operatorname{after}} 2 \mathrm{~h} \\
\end{array}$ \\
\hline $3 \times$ Concentrated control & $100 \pm 2^{\mathrm{b}}$ & $505 \pm 56^{\mathrm{a}}$ & $70 \pm 3^{\mathrm{a}}$ & $1,131 \pm 15^{\mathrm{c}}$ \\
\hline NaCas added before & $103 \pm 3^{\mathrm{b}}$ & $382 \pm 41^{\mathrm{b}}$ & $75.5 \pm 2^{\mathrm{a}}$ & $679 \pm 49^{\mathrm{d}}$ \\
\hline NaCas added after & $\mathrm{ND}^{2}$ & ND & $75.5 \pm 2^{\mathrm{a}}$ & $1,064 \pm 15^{\mathrm{e}}$ \\
\hline
\end{tabular}

${ }^{\mathrm{a}-\mathrm{e}}$ Letters indicate statistical difference $(P<0.05)$ between treatments.

${ }^{1}$ Values are the means $( \pm \mathrm{SE}$ ) of 3 independent experiments. Time of gelation (gel point) was defined for $\tan \delta$ (where $\delta$ is the phase angle) $=1$. The value of elastic modulus $\left(\mathrm{G}^{\prime}\right)$ measured $2 \mathrm{~h}$ after gelation is also shown.

${ }^{2}$ Not detectable. 
rheology and the aggregation time measured by DWS. This is usually not the case in UF or control skim milk (Hemar et al., 2006; Sandra et al., 2007, 2011).

To test whether the lack of gelation in the osmotic stressed samples was due to a change in the accessibility of the rennet enzyme to casein micelles, the release of CMP was tested in the samples concentrated by osmotic stressing (Figure 5). The study of the first stage of the rennet reaction demonstrated that in all the samples concentrated $3 \times$ by osmotic stressing, the release of CMP was not significantly different from that of the control concentrated milk. The area measured from HPLC elution of the serum phase during renneting was higher for samples with NaCas, because of the higher amount of protein. However, in all cases, the extent of hydrolysis was sufficient for gelation to occur (Zoon et al., 1988; Dalgleish, 1992; Sandra et al., 2011). In spite of the near-complete hydrolysis of $\kappa$-casein from the micelles within 80 min, milk with NaCas added after concentration did not show a gelation point (Figures 3 and 4).

It has been previously demonstrated for singlestrength milk that the presence of soluble caseins hinders the rennet-induced gelation of casein micelles by shielding the hydrophobic patches on the particles (Gaygadzhiev et al., 2012). To further evaluate the fate of soluble caseins in the concentrated milk after renneting, the supernatants were separated using centrifugation (see Materials and Methods) after $150 \mathrm{~min}$ from the addition of rennet and analyzed by chromatography (Figure 6). Peaks were assigned as discussed earlier for Figure 1. All elution profiles were similar, irrespective

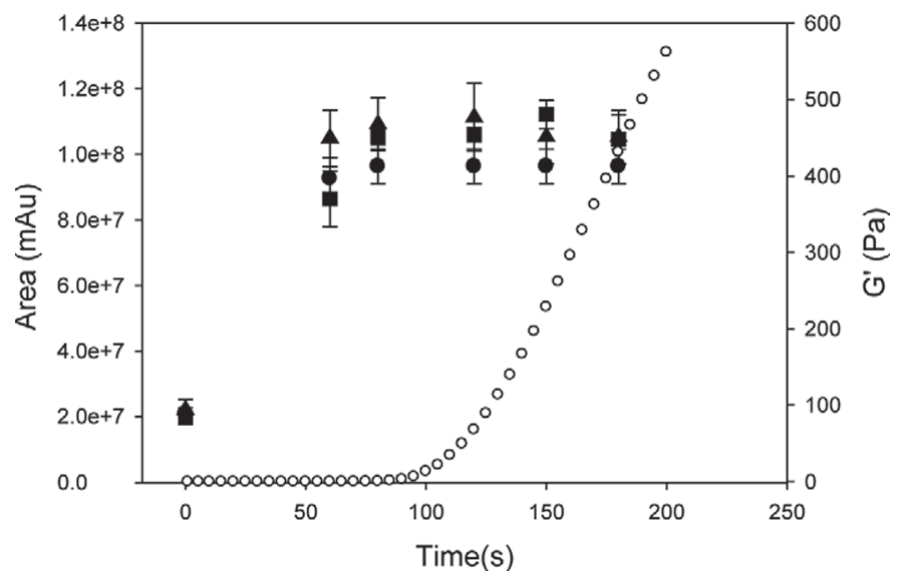

Figure 5. The total peak area of caseinomacropeptide released after the addition of rennet for milk concentrated by osmotic stressing $(\bullet)$ and the same milk with sodium caseinate added before $(\boldsymbol{\Lambda})$ or after ( $)$ concentration. The error bars represent standard error $(\mathrm{n}=$ 3 ).The development of the elastic modulus $\left(\mathrm{G}^{\prime}\right)$ during rennet-induced aggregation for the $3 \times$ milk concentrated by osmotic stressing is also indicated $(\bigcirc)$ as reference.

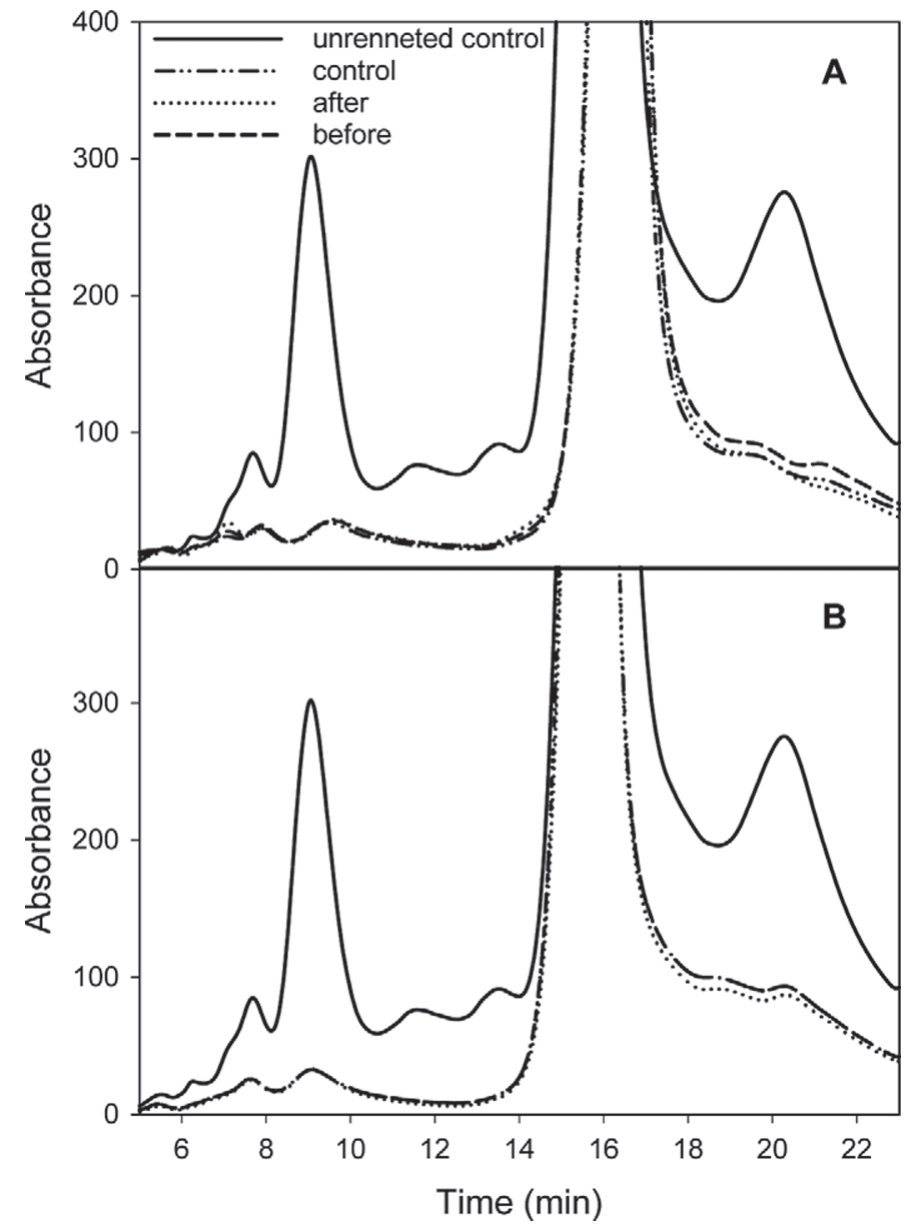

Figure 6. Elution profiles for nonsedimentable proteins before and after renneting of milk concentrated by (A) osmotic stressing or (B) UF. Treatments were control (milk concentrated $3 \times$ ) and milk with sodium caseinate added before or after concentration. For peak assignments, see Figure 1.

of the mode of concentration and presence of NaCas. As previously shown for single-strength milk, although soluble caseins may be present before renneting, these proteins will be associated with the colloidal phase after $\kappa$-casein hydrolysis. These newly associated caseins prevent the secondary stage of aggregation of casein micelles.

\section{CONCLUSIONS}

The results suggest that casein micelles are rearranged during concentration. These findings may have important consequences for researchers and the dairy industry, as membrane filtration is currently considered a gentle process on casein micelles, and casein micelles are often referred to as hard spheres. Casein micelles showed different renneting behaviors depending on the mode of concentration, although the composition of the 
concentrates and apparent radii of casein micelles were similar. When NaCas was added before concentration, regardless of the mode of concentration, the additional protein did not affect the rennet-induced behavior of the casein micelles, despite some differences in the amount of soluble caseins present in the serum phase between osmotic stressing and UF. Profound differences between the concentration methods were observed in milk when sodium casein was added after concentration. In the case of UF milk, rennet-induced gelation showed similarities to that of control milk, whereas in milk concentrated under quiescent conditions, with minimal disturbance, gelation was hindered by the amount of soluble casein added. During concentration, rearrangements of the micelles may occur in addition to selfaggregation of soluble caseins (Pitkowski et al., 2009), resulting in the incorporation of the additional NaCas on the surface or in the porous internal structure of these protein particles. These types of rearrangements have been described before for casein micelles during cooling, whereby $\beta$-casein is released into the serum phase, reassociating when the temperature is increased (Creamer et al., 1977). It is important to note that this research clearly indicated that differences exist in the structure and functionality of caseins concentrated by ultrafiltration or osmotic stressing.

\section{ACKNOWLEDGMENTS}

This work was funded by the Natural Sciences and Engineering Council of Canada and the Ontario Dairy Council, through the Industrial Research Chair program (University of Guelph).

\section{REFERENCES}

Alexander, M., and D. G. Dalgleish. 2004. Application of transmission diffusing wave spectroscopy to the study of gelation of milk by acidification and rennet. Colloids Surf. B Biointerfaces 38:83-90.

Alexander, M., and D. G. Dalgleish. 2007. Diffusing wave spectroscopy of aggregating and gelling systems. Curr. Opin. Colloid Interface Sci. 12:179-186.

Alexander, M., M. Nieh, M. A. Ferrer, and M. Corredig. 2011. Changes in the calcium cluster distribution of ultrafiltered and diafiltered fresh skim milk as observed by small angle neutron scattering. J. Dairy Res. 78:349-356.

Bienvenue, A., R. Jimenez-Flores, and H. Singh. 2003. Rheological properties of concentrated skim milk: Importance of soluble minerals in the changes in viscosity during storage. J. Dairy Sci. 86:3813-3821.

Bouchoux, A., P. Cayemitte, J. Jardin, G. Gésan-Guiziou, and B. Cabane. 2009a. Casein micelle dispersions under osmotic stress. Biophys. J. 96:693-706.

Bouchoux, A., B. Debbou, G. Gesan-Guiziou, M. Famelart, J. Doublier, and B. Cabane. 2009b. Rheology and phase behavior of dense casein micelle dispersions. J. Chem. Phys. 131:165106-165111.

Choi, J., D. S. Horne, and J. A. Lucey. 2007. Effect of insoluble calcium concentration on rennet coagulation properties of milk. J. Dairy Sci. 90:2612-2623.
Creamer, L. K., G. P. Berry, and O. E. Mills. 1977. A study of the dissociation of $\beta$-casein from the bovine casein micelle at low temperature. N. Z. J. Dairy Sci. 12:58-66.

Dahbi, L., M. Alexander, V. Trappe, J. K. G. Dhont, and P. Schurtenberger. 2010. Rheology and structural arrest of casein suspensions. J. Colloid Interface Sci. 342:564-570.

Dalgleish, D. G. 1992. The enzymatic coagulation of milk. Pages 579619 in Advanced Dairy Chemistry. P. F. Fox, ed. Elsevier Applied Science, London, UK.

de Kruif, C. G. 1992. Casein micelles: Diffusivity as a function of renneting time. Langmuir 8:2932-2937.

Farrer, D., and A. Lips. 1999. On the self-assembly of sodium caseinate. Int. Dairy J. 9:281-286.

Ferrer, M. A., M. Alexander, and M. Corredig. 2011. Does ultrafiltration have a lasting effect on the physico-chemical properties of the casein micelles? Dairy Sci. Technol. 91:151-170.

Gaygadzhiev, Z., V. Massel, M. Alexander, and M. Corredig. 2012. Addition of sodium caseinate to skim milk inhibits rennet-induced aggregation of casein micelles. Food Hydrocoll. 26:405-411.

HadjSadok, A.. A. Pitkowski, T. Nicolai, L. Benyahia, and N. MoulaiMostefa. 2008. Characterisation of sodium caseinate as a function of ionic strength, $\mathrm{pH}$ and temperature using static and dynamic light scattering. Food Hydrocoll. 22:1460-1466.

Hemar, Y., H. Singh, and D. S. Horne. 2006. Determination of early stages of rennet induced aggregation of casein micelles by diffusing wave spectroscopy and rheological measurements. Curr. Appl. Phys. 4:362-365.

Henning, D. R., R. J. Baer, A. N. Hassas, and R. Dave. 2004. Major advances in concentrated and dry milk products, cheese, and milk fat based spreads. J. Dairy Sci. 89:1179-1188.

Holland, B., S. Rahimi Yazdi, G. Ion Titapiccolo, and M. Corredig. 2010. Short communication: Separation and quantification of caseins and casein macropeptide using ion-exchange chromatography. J. Dairy Sci. 93:893-900.

Ion Titapiccolo, G., M. Corredig, and M. Alexander. 2010. Modifications to casein micelles renneting functionality caused by non-ionic surfactants. J. Dairy Sci. 93:506-514.

Jenness, R., and J. Koops. 1962. Preparation and properties of a salt solution which simulates milk ultrafiltrate. Neth. Milk Dairy J. 16:153-164.

Karlsson, A. O., R. Ipsen, and Y. Ardö. 2007. Rheological properties and microstructure during rennet induced coagulation of UF concentrated skim milk. Int. Dairy J. 17:674-682.

Kethireddipalli, P., A. R. Hill, and D. G. Dalgleish. 2011. Interaction between casein micelles and whey protein/ $\kappa$-casein complexes during renneting of heat-treated reconstituted skim milk powder and casein micelle/serum mixtures. J. Agric. Food Chem. 59:14421448.

Krall, A. H., and D. A. Weitz. 1998. Internal dynamics and elasticity of fractal colloidal gels. Phys. Rev. Lett. 80:778-781.

López-Fandino, R., M. I. Acedo, and M. Ramos. 1993. Comparative study by HPLC of caseinomacropeptides cows, eves and goats milk. J. Dairy Res. 60:117-121.

Lucey, J. A. 2009. Milk protein gels. Pages 449-481 in Milk Proteins from Expression to Food. A. Thompson and M. Boland, ed. Academic Press/Elsevier, Amsterdam, the Netherlands.

Lucey, J. A., and D. S. Horne. 2009. Milk salts: Technological significance. Pages 351-390 in Advanced Dairy Chemistry. Vol. 3. P. F. Fox, ed. Springer, New York, NY.

McKenna, A. B. 2000. Effect of processing and storage on reconstitution properties of whole milk and ultrafiltered milk powders. $\mathrm{PhD}$ Thesis. Massey University, Palmerston North, New Zealand.

Mellema, M., P. Walstra, J. H. J. van Opheusden, and T. van Vliet. 2002. Effects of structural rearrangements on the rheology of rennet-induced casein particle gels. Adv. Colloid Interface Sci. 98:25-50

Nair, P. K., M. Alexander, D. G. Dalgleish, and M. Corredig. 2014. Physico-chemical properties of casein micelles in unheated skim milk concentrated by osmotic stressing: Interactions and changes in the composition of the serum phase. Food Hydrocoll. 34:46-53. 
Nair, P. K., D. G. Dalgleish, and M. Corredig. 2013. Colloidal properties of heated concentrated milk. Soft Matter 9:3815-3824.

Neville, M. C. 2005. Calcium secretion into milk. J. Mammary Gland Biol. Neoplasia 10:119-128.

Pitkowski, A., T. Nicolai, and D. Durand. 2009. Stability of caseinate solutions in the presence of calcium. Food Hydrocoll. 23:11641168.

Rahimi-Yazdi, S., M. A. Ferrer, and M. Corredig. 2010. Nonsuppressed ion chromatographic determination of total calcium in milk. J. Dairy Sci. 93:1788-1793.

Sandra, S., M. Alexander, and D. G. Dalgleish. 2007. The rennet coagulation mechanism of skim milk as observed by transmission diffusing wave spectroscopy. J. Colloid Interface Sci. 308:364-373.

Sandra, S., C. Cooper, M. Alexander, and M. Corredig. 2011. Coagulation properties of ultrafiltered milk retentates measured using rheology and diffusing wave spectroscopy. Food Res. Int. 44:951-956.

Singh, H. 2007. Interactions of milk proteins during the manufacture of milk powders. Lait 87:413-423.

Srilaorkul, S., L. Ozimek, B. Ooraikul, D. Hadziyev, and F. Wolfe. 1991. Effect of ultrafiltration of skim milk on casein micelle size distribution in retentate. J. Dairy Sci. 74:50-57.
St-Gelais, D., D. Roy, and P. Audet. 1998. Manufacture and composition of low fat Cheddar cheese from milk enriched with different protein concentrate powders. Food Res. Int. 31:137-145.

van Vliet, T., H. J. M. van Dijk, P. Zoon, and P. Walstra. 1991. Relation between syneresis and rheological properties of particle gels. Colloid Polym. Sci. 269:620-627.

Vasbinder, A. J., H. S. Rollema, and C. G. de Kruif. 2003. Impaired rennetability of heated milk; study of enzymatic hydrolysis and gelation kinetics. J. Dairy Sci. 86:1548-1555.

Waungana, A., H. Singh, and R. J. Bennett. 1998. Rennet coagulation properties of skim milk concentrated by ultrafiltration: Effects of heat treatment and $\mathrm{pH}$ adjustment. Food Res. Int. 31:645-651.

Weitz, D. A., and D. J. Pine. 1993. Diffusing-wave spectroscopy. Pages 653-719 in Dynamic Light Scattering: The Method and Some Applications. W. Brown, ed. Oxford Science Publications, Oxford, UK.

Zoon, P., T. van Vliet, and P. Walstra. 1988. Rheological properties of rennet-induced skim milk gels. 3 . The effect of calcium and phosphate. Neth. Milk Dairy J. 42:295-312. 